Research Article

\title{
Local Stability of Trench for Diaphragm Walls Passing through Deep Weak Interlayer
}

\author{
Chen-Liang An, ${ }^{1}$ Wei-Xing Feng, ${ }^{1}$ Qiang-Hu Zhao, ${ }^{2}$ Luo-Luo Ji, \\ De-liang $\mathrm{He}^{3}$ and Ben-Guo $\mathrm{He} \mathbb{D D}^{4}$ \\ ${ }^{1}$ School of Civil Engineering, Shijiazhuang Tiedao University, Shijiazhuang 050043, Hebei, China \\ ${ }^{2}$ CCCC Tunnel Engineering Company, Nanjing 210001, Jiangsu, China \\ ${ }^{3}$ China Railway 14th Bureau Group 4th Engineering Co., LTD, Jinan 250002, China \\ ${ }^{4}$ Key Laboratory of Ministry of Education on Safe Mining of Deep Metal Mines, Northeastern University, \\ Shenyang 110819, China
}

Correspondence should be addressed to Ben-Guo He; hebenguo@mail.neu.edu.cn

Received 4 April 2021; Accepted 20 May 2021; Published 31 May 2021

Academic Editor: Xianjie Hao

Copyright (c) 2021 Chen-Liang An et al. This is an open access article distributed under the Creative Commons Attribution License, which permits unrestricted use, distribution, and reproduction in any medium, provided the original work is properly cited.

\begin{abstract}
When trench construction of the diaphragm wall passes through an ultradeep and weak interlayer, local instability of the trench wall occurs easily. To study the mechanism of the local instability in the trench and by considering the effect of soil arching based on the length of the trench and the angle of internal friction in the weak interlayer, the disturbed area of the trench is defined to be a semiellipse and the local failure stability model of the semiellipse is established. The local stability safety factor of the trench wall is obtained by the limit equilibrium analysis of the model. By conducting parameter sensitivity studies, the results show that the thickness of the overlying strata, the unit weight of the slurry, the angle of internal friction, and the cohesion of the weak interlayer have a great influence on the stability of the trench wall. The semiellipsoid model is used to analyze the stability of the trench wall of the diaphragm wall of a subway station. The calculated results are basically consistent with the field monitoring results. All the work of the paper shows that the model is practical to some extent.
\end{abstract}

\section{Introduction}

Due to the advantages of high overall rigidity, strong resistance to seepage, good adaptability, and small deformation, diaphragm walls are widely used in deep foundation pit projects in water-rich areas [1]. Trench construction is a key process of diaphragm wall construction, and it is also a subject of considerable interest in engineering. Improper excavation of the trench will not only cause excessive surface settlement but also lead to the collapse of the trench wall. In the process of trench construction, slurry pressure is usually used to maintain the stability of the trench wall. When the slurry pressure is insufficient, it readily allows instability in the trench wall [2]. The instability of the trench wall includes overall instability and local instability [3-5].

Elson [6] used indoor tests and Wong [7] and Tamano et al. [8] used field tests to study trench wall stability.
Powrie and Kantartzi carried out a series of centrifugal model tests to study the development law of surface deformation during the excavation of trenches, focusing on the influence of the initial groundwater level and the ratios of the geometrical dimensions of the trench [9]. Tsai et al. proposed that the overall instability model of the slurry trench in cohesionless soil is shell-shaped, and according to the stress balance, the conditions for judging local instability of the trench face were obtained [10]. Oblozinsky et al. used the safety factor to evaluate the overall stability of the trench wall and proposed a practical design method for determining the height of the slurry level and the slurry weight [11]. George et al. analyzed the local stability of the trench wall before the slurry skin was formed and deduced that increasing slurry gravity could provide stability to the trench wall [12]. Fox proposed the Coulomb sliding body model and deduced the analytical solutions for the safety 
factor and critical failure angle of the trench face under the conditions of effective stress and total stress [13]. Jin et al. proposed a theoretical approach to a three-dimensional trench model with an inclined surface, and based on the Coulomb-type force equilibrium, a safety factor assessing the stability was derived [14]. Han and Wang used twodimensional and three-dimensional analysis methods to analyze the local instability of trench faces in weak interlayers [15]. Zhang et al. proposed a limit equilibrium solution for the stability of a slurry-supported trench, where failure was constrained to a finite length [16]. Lei et al. summarized and analyzed the failure modes of slurry trenches, theoretical analysis models and methods of producing slurry trenches, slurry formation and protection mechanisms, the influence of related factors on slurry trench stability, and other related issues [17]. Wang and Maosong used the kinematic method of limit analysis to analyze the stability of a slurry trench in a horizontally layered clayey friction soil [18]. Liu et al. studied the local stability of a slurry trench during seepage, analyzed the influence of seepage on the stability of the trench face, proposed that instability was initiated by the movement of a rigid block with conical discontinuity surfaces, and obtained the upper bound solution of the safety factor $[19,20]$.

In this paper, the Rankine limit equilibrium principle is used to study the local stability of the trench wall when a diaphragm wall passes through an ultradeep weak interlayer. The influences of the parameters of the weak interlayer, trench length, and slurry performance on the local stability of the trench wall are analyzed. A method for calculation of the safety factor is proposed.

\section{Discussion on Disturbed Area of Trenching Construction}

The soil arching effect is a relatively common phenomenon in engineering. After the excavation of a trench, the original balance of the soil is broken. Even under the protection of a slurry, the disturbed soil will move in the direction of the trench section. The movement trend of the soil near the trench wall is obvious. As the distance from the trench wall increases, the movement tendency of the soil gradually decreases. The movement of the soil is hindered by the shear strength of the adjacent soil contact surface. When the distance between the soil and the trench wall reaches a certain value, the shear strength can keep the position of the soil unchanged by reducing the earth pressure of moving soil. This transfer of earth pressure from the moving soil to the adjacent static soil is called the soil arching effect.

Due to the soil arching effect, the soil behind the trench wall forms a natural arch. When the trench wall is unstable, the soil in the natural arch moves toward the trench and reaches the limit equilibrium state; nevertheless, the soils on both sides of the trench wall do not move and are always in a static state. The arching of the trench wall is shown in Figure 1(a). Using the symmetry of Figure 1(a), it can be simplified to Figure 1(b). There is only an axial force at any position of the natural arch, and the bending moment and shear force are both zero. The earth pressure acting on the natural arch along the $Y$ axis is $q_{1}$. According to the Rankine earth pressure theory, the following results are obtained:

$$
q_{1}=q \tan ^{2}\left(45^{\circ}-\frac{\phi}{2}\right) \text {. }
$$

The earth pressure acting on the natural arch along the $X$ axis is $q_{2}$. Since $q_{2}$ is the static earth pressure, according to the formula of static earth pressure, the following results can be obtained:

$$
q_{2}=q(1-\sin \phi)
$$

There is only an axial force acting on any section of a natural arch, and the bending moment and shear force are both zero. In Figure 1(b), the moment is taken from point $B$ to any point $U(x, y)$ on the axis; according to the condition $\sum M_{U}=0$

$$
q_{2} b(b-y)-\frac{1}{2} q_{1} x^{2}-\frac{1}{2} q_{2}(b-y)^{2}=0 .
$$

The following conclusions can be drawn from the calculation:

$$
\frac{x^{2}}{\left(q_{2} / q_{1}\right) b^{2}}+\frac{y^{2}}{b^{2}}=1 .
$$

When $X=a$ and $y=0$, substituting equation (1) leads to the following conclusion:

$$
b=\sqrt{\frac{q_{1}}{q_{2}}} a .
$$

Substituting equations (1) and (2) into equation (5), it can be seen that

$$
b=\frac{1}{\sqrt{2} \sin \left(45^{\circ}+(\phi / 2)\right)} a .
$$

In equations (1)-(6), $q$ is the average value of the uniform distribution $\left(\mathrm{kN} / \mathrm{m}^{2}\right), \varphi$ is the internal friction angle of the soil $(\circ)$, the length of the trench wall is $2 a(m)$, and $b$ is the height of the natural arch $(m)$.

According to the analysis of the soil arch effect, the disturbance caused by the excavation of the trench section of the diaphragm wall is semielliptical. The height of the soil arch is determined by the length of the trench section and the internal friction angle of the soil. The longer the trench section is, the greater the height of the soil arch is; the smaller the internal friction angle of the soil is, the greater the height of the soil arch is.

\section{Local Stability Analysis of Trench Wall}

\subsection{Basic Assumptions}

(1) The soil is isotropic and homogeneous

(2) The sliding surface is rigid and undeformed

(3) The seepage and softening of groundwater are not considered

(4) The sliding surface is an inclined plane 


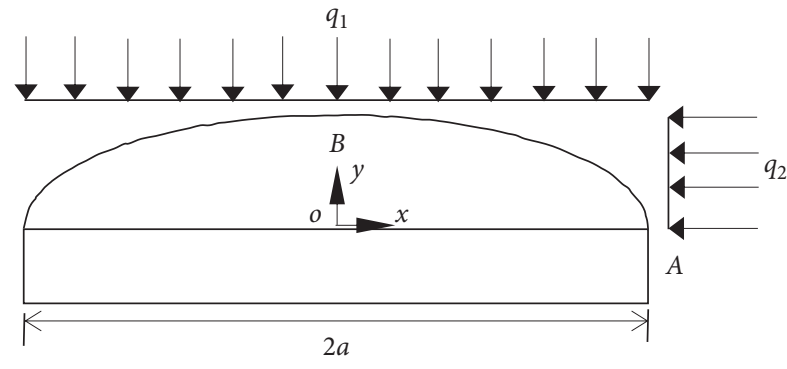

(a)

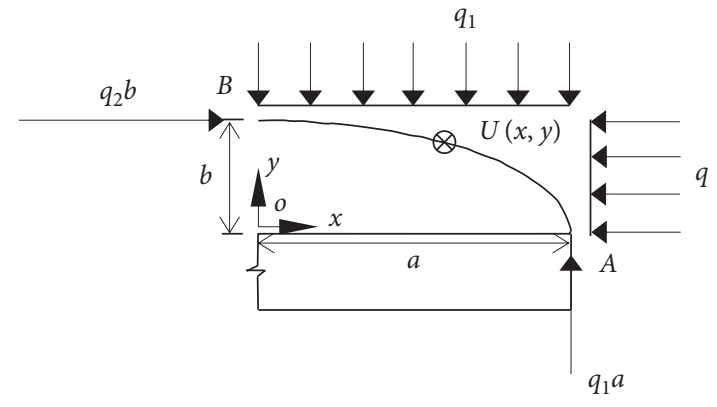

(b)

FIGURE 1: Schematic of trench arching.

3.2. Establishment of the Collapse Body Model. When the diaphragm wall passes through the weak interlayer, the slurry pressure acting on the weak interlayer cannot maintain the stability of the trench wall; this leads to the collapse of soil in the weak interlayer and local instability, as shown in Figure 2. The distance from the slurry to the surface is $Z_{s}$, and the weight of slurry is $\gamma_{s}$; the distance from groundwater to the surface is $Z_{w}$, and the weight of groundwater is $\gamma_{w}$; the thickness of the overlying soil on the weak interlayer is $Z_{1}$, the average weight of the overlying soil is $\gamma_{1}$, and the buoyancy unit weight of the overlying soil is $\gamma_{1}^{\prime}$; the weak interlayer is located below the groundwater level, the thickness of the weak interlayer is $Z_{2}$, the buoyancy unit weight is $\gamma_{2}^{\prime}$, and the cohesion and friction angle are $c$ and $\varphi$, respectively.

From the foregoing, it can be seen that the influence area of the trench construction on the trench wall is semielliptical. According to the plastic limit failure theory, the angle between the sliding surface and the horizontal plane is $\alpha=45^{\circ}+\varphi / 2$ [21]. When the thickness of the weak interlayer $Z_{2}<b-\tan \alpha$, the failure model formed by the instability of the local trench wall is shown in Figure 3 and the length of the trench section is $2 a$.

3.3. Force Analysis of the Collapse Body Model. The forces acting on the failure model include the following: the selfweight of the failure model is $W$, the vertical pressure of the overlying soil is $Q$, the cohesion force of the top surface is $P_{c}$, the friction resistance of the sliding surface is $R$, the lateral friction force is $T$, and the effective slurry supporting force is $P$. The loading analysis of the instability model is shown in Figure 4.

3.3.1. Collapse Body Weight. Since the instability model is located below the groundwater level, the weight of the collapse body is equal to the volume multiplied by the buoyancy unit weight of the soil. First, the volume of the collapse body is determined. The top surface area of the collapse body is calculated as follows:

$$
S_{C D E F}=\frac{a}{b}\left(z_{2} \cot \alpha\right) \sqrt{b^{2}-\left(z_{2} \cot \alpha\right)^{2}}+a b \arcsin \left(\frac{z_{2} \cot \alpha}{b}\right) \text {. }
$$

The volume of the collapse body is as follows:

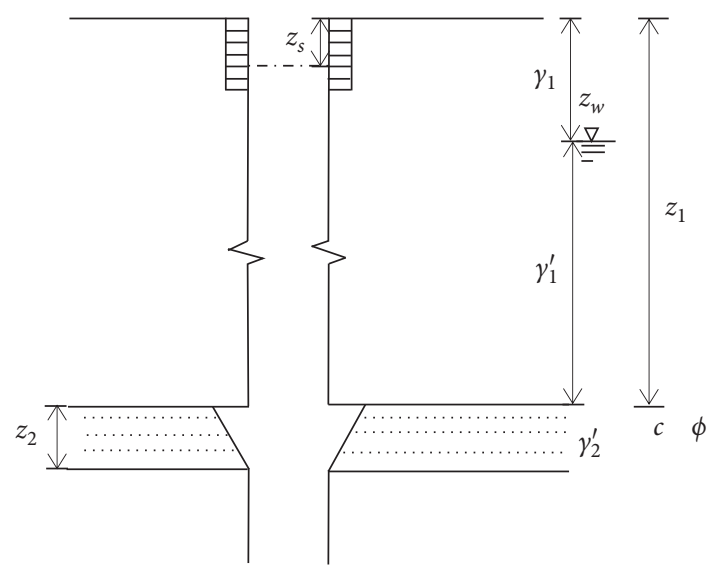

FIGURE 2: Diaphragm wall passing through weak interlayer.

$$
V=S_{C D E F} z_{2}-\left(\frac{2 a z_{2}^{2} \cot \alpha}{3}\right) .
$$

The weight of the collapse body is as follows:

$$
W=V \gamma_{2}^{\prime}
$$

3.3.2. Vertical Pressure of Overlying Soil. The vertical pressure of the overlying soil layer over the instability model is the force acting on the CDEF area on the top surface by the surface load and the weight of the overlying soil. Taking into account the space effect of the trench wall, Huder [22] corrected the vertical stress caused by its own weight, and the correction factor is as follows:

$$
A=\frac{1-\exp \left(-2 n K_{a} \tan \phi\right)}{2 n K_{a} \tan \phi} .
$$

The vertical stress acting on the CDEF plane is as follows:

$$
\sigma_{v}=A\left[\gamma_{1} z_{w}+\gamma_{1}^{\prime}\left(z_{1}-z_{w}\right)+q\right] .
$$

The vertical pressure on the top surface $C D E F$ of the instability model is as follows:

$$
Q=\sigma_{v} S_{C D E F} .
$$

In equations (9)-(10), $\quad n=z_{1} /(2 a), \quad K_{a}=\tan ^{2}(45-$ $(\phi / 2)), K_{a}$ is the coefficient of earth pressure, $q$ is the 


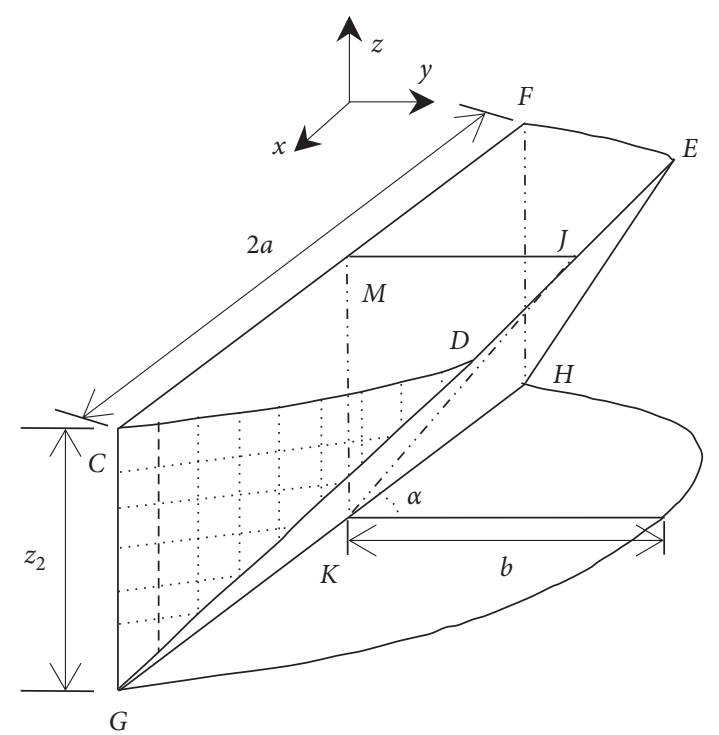

FIgURE 3: Local instability failure model.

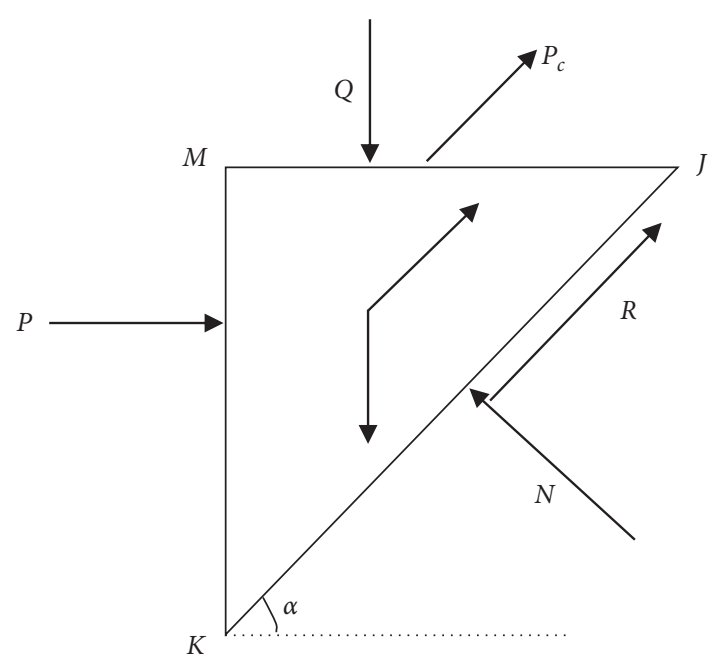

FIgURE 4: Loading analysis of the instability model.

uniform load on the ground $\left(\mathrm{kN} / \mathrm{m}^{2}\right)$, and the other symbols are defined as above.

\subsubsection{Cohesion on the Top Surface of the Collapse Body}

$$
P_{c}=c S_{C D E F},
$$

where $c$ is the cohesion of the weak interlayer $(\mathrm{kPa})$.

3.3.4. Side Friction. The collapse body is discretized into tiny steps along the $Y$ axis along the top surface $\operatorname{arc} C D$. When the collapse body slides along the inclined sliding surface, there is a tensile stress on the step surface parallel to the $X$ axis direction, which can be ignored, parallel to $Y$ direction. The projection of the friction in the axial direction is $M J$, as shown in Figure 5. The profiles of the $C D G$ and FEH surfaces are projected on the $Y Z$ plane, and the side friction is calculated with the projected area $M J K$. The friction resistance is composed of friction and

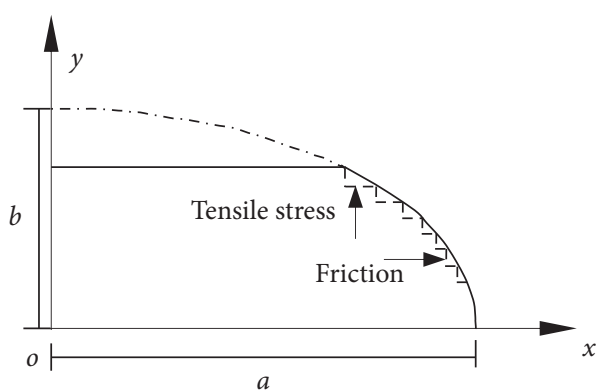

FIGURE 5: Lateral force area of the collapsed body.

cohesion acting on the side. The average horizontal stress acting on profiles $C D G$ and $F E H$ is as follows:

$$
\sigma_{h}=\left(\sigma_{v}+\frac{1}{3} z_{2} \gamma_{2}^{\prime}\right) K_{0},
$$

where $K_{0}$ is the coefficient of static earth pressure, $K_{0}=1-\sin \phi$.

The frictional resistance on profiles $C D G$ and $F E H$ is as follows:

$$
T=\left(\sigma_{h} \tan \phi+c\right) z_{2}^{2} \cot \alpha .
$$

3.3.5. Effective Supporting Pressure of Slurry. The effective supporting pressure of the slurry is the combined forces of slurry pressure and groundwater pressure on the trench wall. The slurry pressure acting on $C F H G$ is as follows:

$$
P=z_{2}^{2} a\left[\gamma_{s}\left(\left(2 z_{1}+z_{2}\right)-2 z_{s}\right)-\gamma_{w}\left(\left(2 z_{1}+z_{2}\right)-2 z_{w}\right)\right] .
$$

3.3.6. Friction of Sliding Surface. The friction resistance acting on the sliding surface $D E H G$ is composed of friction and cohesion. The force balance equation in the normal direction of the sliding surface is as follows:

$$
N=(W+Q) \cos \alpha+P \sin \alpha .
$$

The frictional resistance on the sliding surface is as follows:

$$
R=N \tan \phi+\left(\frac{c S_{C D E F}}{\cos \alpha}\right)
$$

The equilibrium equation established along the tangent direction of the sliding surface is as follows:

$$
P \cos \alpha+P_{c}+T+R=(W+Q) \sin \alpha .
$$

Substituting equations (17) and (18) into equation (19), the safety factor of the trench wall can be obtained as follows:

$$
F_{s}=\left(\frac{P(\sin \alpha \tan \phi+\cos \alpha)+\left(P_{c}+T+R\right)}{(W+Q) \sin \alpha}\right)+\tan \phi \cot \alpha \text {. }
$$

3.4. Analysis of Influence Factors for Local Stability of Trench Walls. It is assumed that the relevant parameters of the trench wall and stratum are as follows: the length of the 
trench section is $2 a=6 \mathrm{~m}$; the depth of the trench is $50 \mathrm{~m}$; the mud weight $\gamma_{s}=11 \mathrm{kN} / \mathrm{m}^{3}$; the slurry level is flush with the ground; the distance from groundwater level to ground surface is $z_{w}=3 \mathrm{~m}$; the ground water weight $\gamma_{W}=10 \mathrm{kN} / \mathrm{m}^{3}$; the overlying soil layer is homogeneous, with the gravity $\gamma_{1}=20 \mathrm{kN} / \mathrm{m}^{3}$, and the buoyant gravity $\gamma_{1}^{\prime}=10 \mathrm{kN} / \mathrm{m}^{3}$; the buoyant gravity of the weak interlayer is $\gamma_{2}^{\prime}=9 \mathrm{kN} / \mathrm{m}^{3}$; cohesion $c=0 \mathrm{kPa}$; the internal friction angle $\phi=30^{\circ}$; and the thickness of the weak interlayer is $z_{2}=1 \mathrm{~m}$ This paper analyzes the influences of variations in the parameters on the local safety factor of the trough wall when the soil thickness of the weak interlayer is $20 \mathrm{~m}, 30 \mathrm{~m}, 40 \mathrm{~m}$, or $50 \mathrm{~m}$.

3.4.1. Influence of the Weak Interlayer on the Local Stability of the Trench Wall. Figure 6 shows the variations in the safety factor with the cohesion, internal friction angle, and thickness of the weak interlayer.

As shown in Figure 6, as the cohesion of the weak interlayer increases, the safety factor gradually increases, and the relationship between them is linear. When the cohesion increases from $0 \mathrm{kPa}$ to $30 \mathrm{kPa}$, the safety factors for the thickness of the overburden soil at $20 \mathrm{~m}, 30 \mathrm{~m}, 40 \mathrm{~m}$, and $50 \mathrm{~m}$ increase by $0.77,0.68,0.64$, and 0.63 , respectively, indicating that cohesion plays an important role in stabilizing the trench wall. The smaller the cohesion is, the worse the stability of the trench wall is. The greater the cohesion is, the better the stability of the trench wall is. As far as the thickness of the overburden soil is concerned, the safety factors at the thicknesses $20 \mathrm{~m}$ and $30 \mathrm{~m}$ are basically the same; the safety factor difference between the thicknesses at $30 \mathrm{~m}$ and $40 \mathrm{~m}$ assumes a certain value, which does not change with increasing cohesion.

Figure 7 shows that as the internal friction angle of the weak interlayer increases, the local safety factor of the trench wall gradually increases, and the two basically exhibit a linear relationship. When the internal friction angle increases from $10^{\circ}$ to $30^{\circ}$, the safety factors at the $20 \mathrm{~m}, 30 \mathrm{~m}, 40 \mathrm{~m}$, and $50 \mathrm{~m}$ thicknesses of the overburden soil increase by $0.58,0.63$, 0.69 , and 0.76 , respectively. This shows that the internal friction angle has a very important effect on the local stability of the trench wall. When the internal friction angle is small, the thickness of the overburden soil increases, and the increase in the safety factor is small. When the friction angle is great, the thickness of the overburden soil increases, and the safety factor gradually increases.

As shown in Figure 8, when the thickness of the weak interlayer is constant, as the thickness of the overburden soil increases, the safety factor gradually increases. When the thickness of the weak interlayer is small, the safety factor is small; when the thickness of the weak interlayer is great, the safety factor is also great. When the thickness of the weak interlayer increases from $0.5 \mathrm{~m}$ to $4.0 \mathrm{~m}$, the safety factors for the covering soil thicknesses of $20 \mathrm{~m}, 30 \mathrm{~m}, 40 \mathrm{~m}$, and $50 \mathrm{~m}$ increase by $0.31,0.32,0.33$, and 0.35 , respectively. Compared with the cohesion and internal friction angle of the weak interlayer, the thickness of the weak interlayer has a relatively small effect on the stability of the trench.

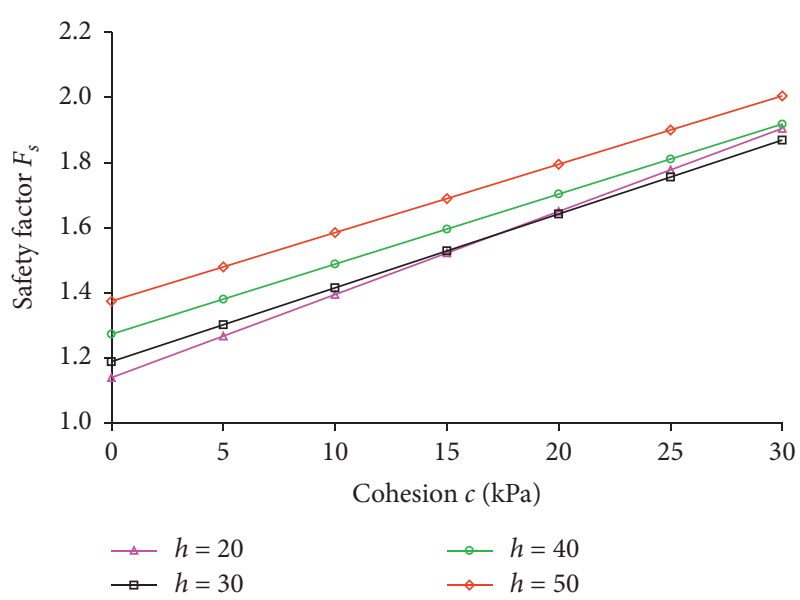

FIGURE 6: Relationship between the safety factor and cohesion of the weak interlayer.

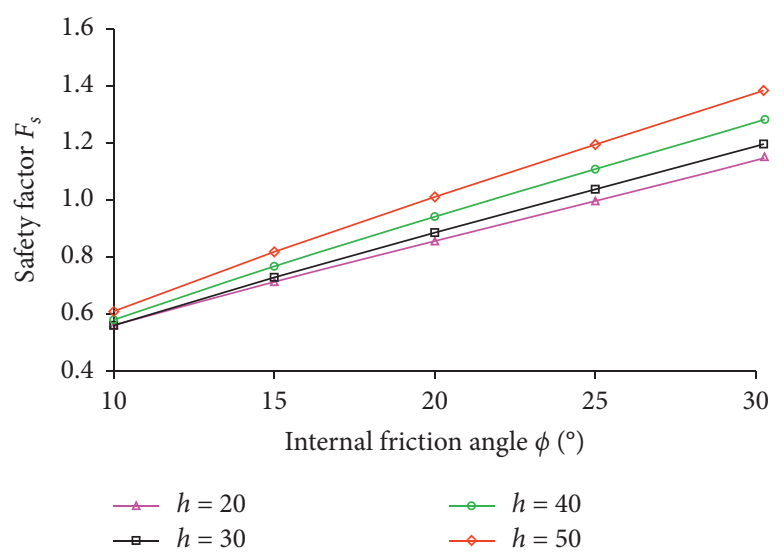

Figure 7: Relationship between the safety factor and internal friction angle of the weak interlayer.

3.4.2. Influence of Slurry on Local Stability of Trench Wall. Figure 9 shows the variations in the safety factor with changes in slurry gravity and level. When the slurry gravity is constant, the greater the overburden soil thickness is, the greater the safety factor is and the greater the stability of the trench wall is. With increasing slurry gravity, the local safety factor of the trench wall increases gradually, and the relationship between them is linear. When the slurry gravity increased from $10.5 \mathrm{kN} / \mathrm{m}^{3}$ to $13.0 \mathrm{kN} / \mathrm{m}^{3}$, the safety factors increased by 0.77 for thickness of overburden soil $20 \mathrm{~m}, 1.02$ for thickness of overburden soil $30 \mathrm{~m}, 1.29$ for thickness of overburden soil $40 \mathrm{~m}$, and 1.57 for thickness of overburden soil $50 \mathrm{~m}$, respectively. Therefore, during the construction of the trench, the slurry gravity can be appropriately increased to ensure the stability of the trench wall. The newly prepared slurry gravity is not less than $10.5 \mathrm{kN} / \mathrm{m}^{3}$. However, if the slurry gravity is too great, the fluidity of the mud will become poor, which not only affects the pouring of concrete but also makes it difficult to pump the concrete. The slurry gravity after cleaning is generally not greater than $11.5 \mathrm{kN} / \mathrm{m}^{3}$.

As shown in Figure 10, when the slurry level is constant, the greater the overburden soil thickness of the weak 


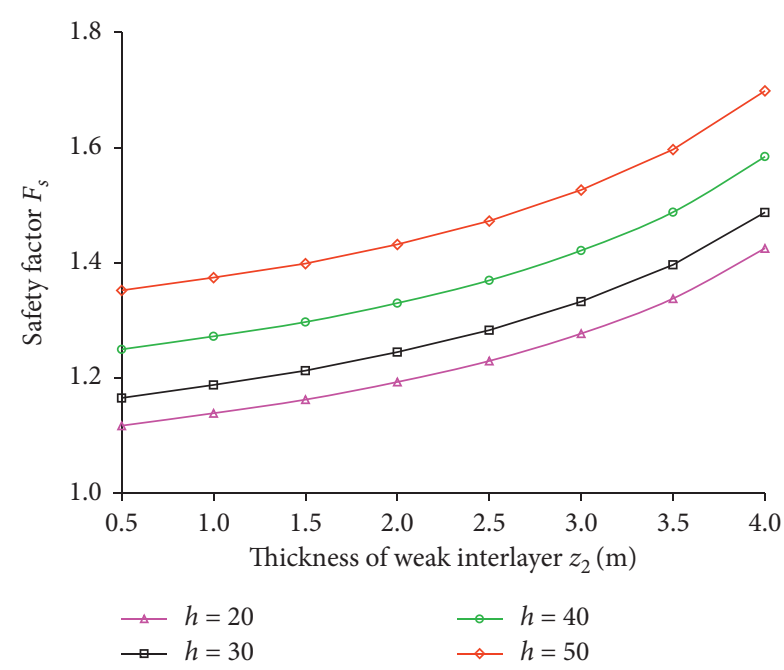

FIgURE 8: Relationship between the safety factor and thickness of the weak interlayer.

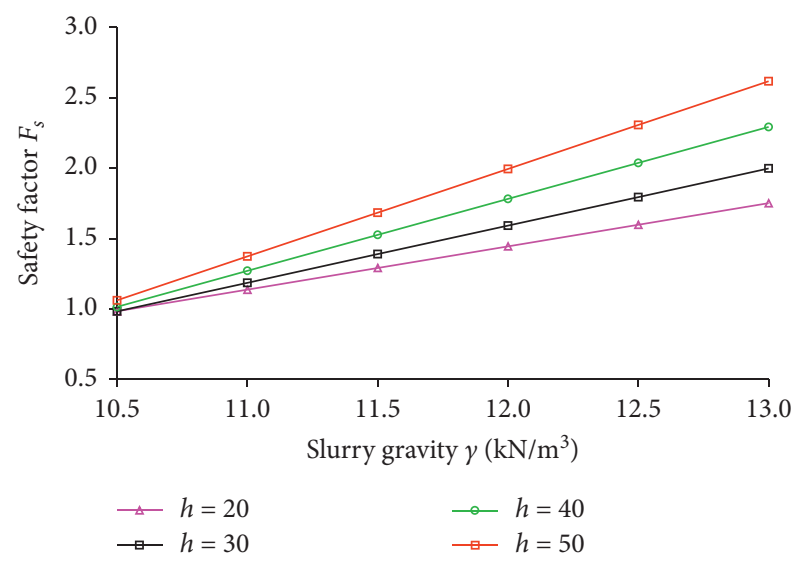

FIGURE 9: Relationship between the safety factor and slurry gravity.

interlayer is, the greater the safety factor is. As the depth of the slurry level increases, the safety factor gradually decreases, and the relationship between the two is linear. When the depth of the slurry level increases from the surface to $2.5 \mathrm{~m}$, the safety factors at the covering soil thicknesses of $20 \mathrm{~m}, 30 \mathrm{~m}, 40 \mathrm{~m}$, and $50 \mathrm{~m}$ are reduced by $0.41,0.37,0.35$, and 0.34 , respectively. Therefore, during the construction of the trench, to ensure the stability of the trench wall, the slurry level can be flush with the top surface of the guide wall.

\subsubsection{Influence of Trench Section Length on Local Stability of} Trench Wall. Figure 11 shows the variation law of the safety factor as a function of the length of the trench section. When the length of the trench section is constant, the greater the overburden soil thickness is, the greater the safety factor is. As the length of the trench section increases, the safety factor gradually decreases. When the length of the trench section is increased from $4.0 \mathrm{~m}$ to $7.0 \mathrm{~m}$, the local safety factors of the trench wall at thicknesses of $20 \mathrm{~m}, 30 \mathrm{~m}, 40 \mathrm{~m}$, and $50 \mathrm{~m}$ are reduced by $0.32,0.43,0.53$, and 0.63 , respectively. The length

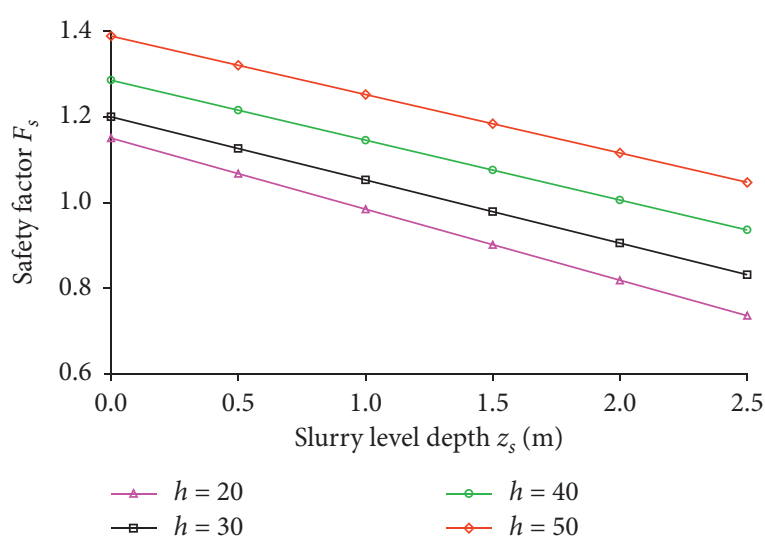

Figure 10: Relationship between safety factor and slurry level depth.

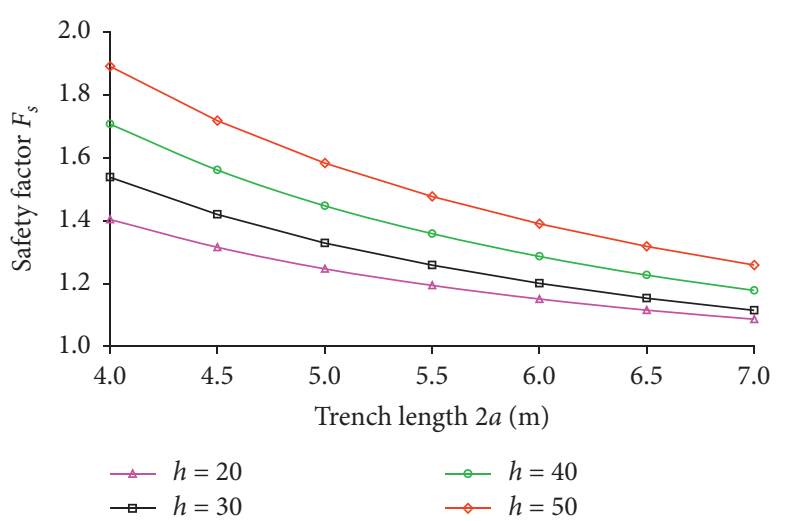

FIgURE 11: Relationship between the safety factor and trench length.

of the trench section should not exceed $6 \mathrm{~m}$ during the construction of the trench.

\section{Case Study}

The deep foundation pit of a certain station adopts the diaphragm wall as the retaining structure. The diaphragm wall is $30 \mathrm{~m}$ deep, and the single trench section is $6 \mathrm{~m}$ long and $800 \mathrm{~mm}$ thick. The landform type of the site belongs to the alluvial plain of the Yangtze River Delta, the terrain is relatively flat, the ground elevation is generally $2.0 \sim 6.5 \mathrm{~m}$, and the buried depth of the groundwater level is $3 \mathrm{~m}$. The stratum of the site is dominated by soft soil, and the depth, thickness, and performance of the soil layer vary greatly. The strata from top to bottom are (1) filled soil, (2) sandy silt, (3) silty sand, (4) 1 silty clay, (4) 2 muddy clay, (5) 1 silt, and (5) 2 silty clay with sand. The physical and mechanical parameters of the soil layer are shown in Table 1.

According to the stratigraphic parameters in this area, due to the high silt contents of (4) 2 and (5) 1 , the cohesion and internal friction angle are small, and local instability easily occurs. The safety factor calculation method in this paper is used to analyze the stability of the trench wall in formations (4) 2 and (5) 1 . 
Table 1: Physical and mechanical parameters of strata.

\begin{tabular}{|c|c|c|c|c|}
\hline Strata & Thickness, $z(\mathrm{~m})$ & Gravity, $\gamma\left(\mathrm{kN} / \mathrm{m}^{3}\right)$ & Cohesion, $c(\mathrm{kPa})$ & Friction angle, $\varphi\left({ }^{\circ}\right)$ \\
\hline (1) filled soil & 2.63 & 19.0 & - & - \\
\hline (2) sandy silt & 1.56 & 19.0 & 6.9 & 29.5 \\
\hline (3) silty sand & 7.61 & 19.3 & 6.4 & 30.0 \\
\hline (4) 1 silty clay & 11.40 & 17.6 & 17.9 & 18.6 \\
\hline (4) 2 muddy clay & 3.00 & 17.7 & 13.8 & 13.1 \\
\hline (5) 1 silt & 2.00 & 18.4 & 6.1 & 12.8 \\
\hline (5) 2 silty clay with sand & 5.36 & 17.8 & 22.1 & 13.8 \\
\hline
\end{tabular}

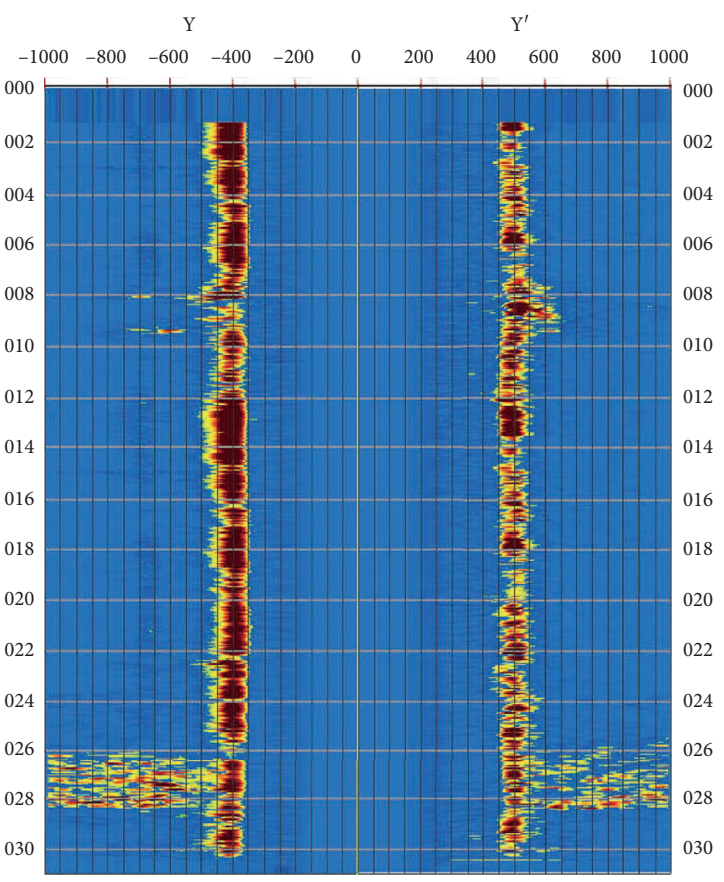

Figure 12: Ultrasonic detection atlas.

For the stability analysis of the (4) 2 layer trench wall, the thickness of the overburden soil is $23.2 \mathrm{~m}$, the average severity is $18.45 \mathrm{kN} / \mathrm{m}^{3}$, and the angle of internal friction is $13.1^{\circ}$. The thickness of the weak interlayer is $3 \mathrm{~m}$, the weight is $17.7 \mathrm{kN} / \mathrm{m}^{3}$, the cohesion is $13.8 \mathrm{kPa}$, the internal friction angle is $13.1^{\circ}$, and the slurry weight is $10.5 \mathrm{kN} / \mathrm{m}^{3}$. The calculation shows that $F_{s}=1.25$, so the trench wall of the (4) 2 layer is safe.

For the stability analysis of the (5) 1 layer trench wall, the thickness of the overburden soil is $26.2 \mathrm{~m}$, the average severity is $18.33 \mathrm{kN} / \mathrm{m}^{3}$, and the angle of internal friction is $13.1^{\circ}$. The thickness of the weak interlayer is $2 \mathrm{~m}$, the weight is $18.4 \mathrm{kN} / \mathrm{m}^{3}$, the cohesion is $6.1 \mathrm{kPa}$, the internal friction angle is $12.8^{\circ}$, and the slurry weight is $10.5 \mathrm{kN} / \mathrm{m}^{3}$. The calculation shows that $F_{s}=0.84<1.0$, so the trench wall of the (5) 1 layer easily loses stability.

When the construction of the trench was completed, the quality of the trench wall was inspected by ultrasonic methods, and the test results are shown in Figure 12. Trench wall collapse occurred at burial depths of 26-28 m, and the stability of the trench wall at other locations was better. The results of ultrasonic testing effectively verified the safety factor proposed in this paper.

\section{Conclusions}

This paper reports an extensive study on the local stability of the slurry wall trench of a diaphragm wall. The following conclusions are obtained:

(1) The disturbance area caused by trench construction is semielliptical, and the size of the semiellipse is related to the length of the trench section and the angle of internal friction of the soil. The greater the length of the trench section and the internal friction angle of the soil, the greater the disturbance area, which is unfavorable for the stability of the trench wall.

(2) Based on the Rankine limit equilibrium principle, a three-dimensional calculation model for the local instability of the trench wall was created. The method for calculating the local stability safety factor of the trench wall was deduced for the situation in which the diaphragm wall passed through the ultradeep weak interlayer. The calculation method of the safety factor was verified by an engineering example, which proves that the model is practical and can predict the local instability of the trench wall.

(3) When the diaphragm wall passes through the ultradeep weak interlayer, local instability of the trench wall is prone to occur. The greater the thickness of the overburden, the better the stability of the trench wall. The greater the cohesion and internal friction angle of the weak interlayer, the better the stability of the trench wall. The greater the slurry gravity is, the better the stability of the trench wall is. The higher the slurry level is, the better the stability of the trench wall is. The greater the length of the trench section is, the worse the stability of the trench wall is.

(4) The top surface of the local instability model constructed in this paper is a regular plane, which is different from the actual collapsed body. The influence of groundwater seepage was not considered in the force analysis of the instability model. In the next step, the local safety factor of the trench wall should be analyzed based on the shape characteristics of the local instability model and the influence of groundwater seepage.

\section{Data Availability}

The data used to support the findings of this study are included in the article. 


\section{Conflicts of Interest}

The authors declare that they have no conflicts of interest.

\section{Acknowledgments}

This study was supported by the National Key Research and Development Program of China (2018YFC0407006), the Young Scientists Fund of the National Natural Science Foundation of China (51809038), the Postgraduate Innovation Funding Project of Hebei Province (CXZZBS2019153), and the Fundamental Research Funds for the Central Universities (N2001009).

\section{References}

[1] Y.-C. Li, Q. Pan, P. J. Cleall, Y.-M. Chen, and H. Ke, "Stability analysis of slurry trenches in similar layered soils," Journal of Geotechnical and Geoenvironmental Engineering, vol. 139, no. 12, pp. 2104-2109, 2013.

[2] Y. C. Ding and J. H. Wang, "Numerical modelling of ground response during diaphragm wall construction," Journal of Shanghai Jiaotong University, vol. 13, no. 4, pp. 1-6, 2017.

[3] N. Morgenstern and I. Amir-Tahmasseb, "The stability of a slurry trench in cohesionless soils," Géotechnique, vol. 15, no. 4, pp. 387-395, 1965.

[4] J.-S. Tsai, "Stability of weak sublayers in a slurry supported trench," Canadian Geotechnical Journal, vol. 34, no. 2, pp. 189-196, 1997.

[5] C.-Y. Han, J.-J. Chen, J.-H. Wang, and X.-H. Xia, "2D and 3D stability analysis of slurry trench in frictional/cohesive soil," Journal of Zhejiang University Science A, vol. 14, no. 2, pp. 94-100, 2013.

[6] W. K. Elson, "An experimental investigation of the stability of slurry trenches," Géotechnique, vol. 18, no. 3, pp. 37-49, 1968.

[7] G. C. Y. Wong, "Stability analysis of slurry trenches," Journal of Geotechnical Engineering, vol. 110, no. 11, pp. 1557-1590, 1984.

[8] T. Tamano, S. Fukui, H. Suzuki, and K. Ueshita, "Stability of slurry trench excavation in soft clay," Soils and Foundations, vol. 36, no. 2, pp. 101-110, 1996.

[9] W. Powrie and C. Kantartzi, "Ground response during diaphragm wall installation in clay: centrifuge model test," Géotechnique, vol. 46, no. 4, pp. 725-739, 1996.

[10] J. S. Tsai, C. C. Chang, and L. D. Jou, "Lateral extrusion analysis of sandwichen weak soil in slurry trench," Journal of Geotechnical and Geo-Environmental Engineering, vol. 124, no. 11, pp. 1082-1090, 1998.

[11] P. Oblozinsky, K. K. M. Ugai, M. Katagiri et al., “A design method for slurry trench wall stability in sandy ground based on the elastoplastic FEM," Computers and Geotechnics, vol. 28, no. 2, pp. 145-159, 2001.

[12] M. F. George, A. Tiffany, and R. D. Richard, "Stability of long trenches in sand supported by bentonite-water slurry," Journal of Geotechnical and Geoenvironmental Engineering, vol. 130, no. 9, pp. 915-921, 2004.

[13] P. J. Fox, "Analytical solutions for stability of slurry trench," Journal of Geotechnical and Geoenvironmental Engineering, vol. 130, no. 7, pp. 749-758, 2004.

[14] X. Jin, S. Liang, and X. Zhu, "Stability of three-dimensional slurry trenches with inclined ground surface: a theoretical study," Advances in Materials Science and Engineering, vol. 2015, Article ID 362160, 8 pages, 2015.
[15] C. Y. Han and J. H. Wang, "Limit analysis for local and overall stability of a slurry trench in cohesive soil," International Journal of Geomechanics (ASCE), vol. 15, no. 5, Article ID 06104026, 2015.

[16] F. Zhang, Y. F. Gao, and D. Leshchinsky, "Three-dimensional stability of slurry-supported trenches: end effects," Computers and Geotechnics, vol. 74, pp. 174-187, 2016.

[17] M. Lei, L. Liu, and L. Yuexiang, "Research progress on stability of slurry wall trench of underground diaphragm wall and design method of slurry unit weight," Advances in Civil Engineering, vol. 2019, Article ID 3965374, 19 pages, 2019.

[18] H. Wang and H. Maosong, "Upper bound stability analysis of slurry-supported trenches in layered soils," Computers and Geotechnics, vol. 122, p. 9, Article ID 103554, 2020.

[19] W. Liu, P. Shi, and P. Gan, "A three-dimensional mechanism for global stability of slurry trench in frictional soils," $E u$ ropean Journal of Environmental and Civil Engineering, vol. 23, no. 9, pp. 1-26, 2019.

[20] W. Liu, P. Shi, P. Gan, and C. Cao, "Seepage on local stability of slurry trench in deep excavation of diaphragm wall construction," Computers and Geotechnics, vol. 129, p. 13, Article ID 103878, 2021.

[21] Y. Ding, G. Li, Z. Cheng et al., "Analysis of trench face stability of diaphragm wall panel during slurry trenching," Chinese Journal of Rock Mechanics and Engineering, vol. 32, no. 1, pp. 2704-2709, 2013.

[22] J. Huder, "Stability of bentonite slurry trenches with some experiences in Swiss practice," in Proceedings of the 5th European Conference on Soil Mechanics and Foundation Engineering, pp. 517-522, Madrid, Spain, April 1972. 